\title{
Strong and $\Delta$-Convergence Results for Generalized Multi-valued Non-expansive Maps in CAT (0) Spaces
}

\author{
Fiaz Hussain $^{1, *}$, Saima Zainab ${ }^{2}$ \\ ${ }^{1}$ Department of Mathematics, the Islamia University of Bahawalpur, Pakistan \\ ${ }^{2}$ Center for Advanced Studies in Pure and Applied Mathematics, Bahauddin Zakariya University Multan, Pakistan
}

Copyright $\subset 2017$ by authors, all rights reserved. Authors agree that this article remains permanently open access under the terms of the Creative Commons Attribution License 4.0 International License

\begin{abstract}
In this paper, we establish strong convergence and $\Delta$-convergence theorems for the class of generalized non-expansive multi-valued maps in a $C A T(0)$ space. Our work extends and improves some recent results announced in the current literature.
\end{abstract}

Keywords Multi-valued Map, Fixed Point, Asymptotic Centre, Strong Convergence, $\Delta$-convergence

\section{Introduction}

Let $D$ be a nonempty subset of a metric space $(X, d)$ and $T: D \rightarrow D$ be a map. Then $T$ is: (i) non-expansive if $d(T x, T$ $y) \leq d(x, y)$ for all $x, y \in D$; (ii) quasi non-expansive if $d(T x, p) \leq d(x, p)$ for all $x \in D$ and for all $p \in F(T)$, where $F(T)=\{x \in D: T x=x\}$. Over the past few decades, fixed point theory for non-expansive maps fascinated many researchers due to the applicability of non-expansive maps in various disciplines of science. In 2008, Suzuki [17] introduced a condition known as condition $(C)$, which is weaker than the non-expansiveness and stronger than the quasi-non-expansiveness. Moreover, he obtained some interesting fixed point theorems and convergence theorems for such maps in a Banach space.

Recall that a set $D$ is proximinal if for each $x \in X$, there exists an element $y \in D$ such that $d(x, y)=d(x, D)$, where $d(x, D)=\inf \{d(x, z): z \in D\}$. Let $C B(D) ; K(D)$ and $P(D)$ denote the families of nonempty closed bounded subsets, nonempty compact subsets and nonempty proximinal bounded subsets of $\mathrm{D}$ respectively. The Housdorff metric on $C B(D)$ is defined as:

$$
H(A, B)=\max \left\{\sup _{\mathrm{x} \in \mathrm{A}} \mathrm{d}(\mathrm{x}, \mathrm{B}), \sup _{\mathrm{y} \in \mathrm{B}} \mathrm{d}(\mathrm{y}, \mathrm{A})\right\},
$$

for all $\mathrm{A}, \mathrm{B} \in \mathrm{CB}(\mathrm{D})$.

A multi-valued map $T: D \rightarrow C B(D)$ is said to be non-expansive if $H(T x, T y) \leq d(x, y)$ for all $x, y \in D$. An element $p \in D$ is said to be fixed point of the multi-valued map $T$ if $p \in T p$. Quite recently, Zuo and Cui [19] introduced the following multi-valued version of condition
$(C)$ :

A multi-valued map $T$ defined on a nonempty subset $D$ of a Banach space $E$ is said to satisfy condition (C), if

$$
\begin{gathered}
\frac{1}{2} \operatorname{dist}(x, T x) \leq d(x, y) \text { implies } H(T x, T y) \\
\leq d(x, y) \text { for all } x, y \in D
\end{gathered}
$$

where $d$ is induced by the norm.

Obviously, the above condition is weaker than the multi-valued non-expansive map (with respect to the Hausdroff metric $H$ ). Indeed, if we define a map $T$ on $[0,3]$ by

$$
T x=\left\{\begin{array}{l}
\{0\} \text { if } x \neq 3, \\
{[0,1] \text { if } x=3 .}
\end{array}\right.
$$

Then $T$ satisfies condition (C), but $T$ is not multi-valued non-expansive map.

A metric space $X$ is a $C A T(0)$ space if it is geodesically connected, and if every geodesic triangle in $X$ is at least as "thin" as its comparison triangle in the Euclidean plane. It is well known that any complete, simply connected Riemannian manifold having non-positive sectional curvature is a $C A T(0)$ space. Other examples are Pre-Hilbert spaces, $R$-trees [1], Euclidean buildings [2] the complex Hilbert ball with a hyperbolic metric [8] and many others. In recent years $C A T(0)$ spaces have attracted the attention of many authors as they have played a very vital role in different aspects of geometry. The precise definition is given in section 2. A very thorough discussion of these spaces and the role they play in geometry can be found in [1].

As, it was noted by W.A. Kirk in his fundamental results $[11,12]$ that the geometry of $C A T(0)$ spaces is rich enough to develop a very consistent theory on fixed point under metric conditions. The work were followed by a series of new works by various authors (see for instance $[4,6,10,13]$ ) mainly focusing on $C A T(0)$ spaces and $R$-trees due to the particularly rich geometry of both classes of spaces.

Recently, Phuengrattana [18] established weak and strong convergence theorems for maps satisfying condition $(C)$ in a Banach space as well as in $C A T(0)$ spaces.

Inspired and motivated by the work of Suzuki [17], 
Phuengrattana [18], Zuo and Cui [19], we propose and analyze the following two-step algorithm for multi-valued generalized non-expansive maps for strong convergence and $\Delta$-convergence results in a $C A T(0)$ space.

For an initial guess $x_{0} \in D$, we generate a sequence $\left\{x_{n}\right\}$ by the following algorithm:

$$
\begin{aligned}
& y_{n}=\alpha_{n} T x_{n} \oplus\left(1-\alpha_{n}\right) x_{n}, \\
& x_{n+1}=\beta_{n} z_{n}^{\prime} \oplus\left(1-\beta_{n}\right) T x_{n},
\end{aligned}
$$

where $z_{n}^{\prime} \in S y_{n}$ for all $n \geq 0$.

\section{Preliminaries}

Let $(X, d)$ be a metric space. A geodesic path joining $x \in X$ to $y \in X$ (or, more briefly, a geodesic from $x$ to $y$ ) is a map $c$ from a closed interval $[0, l] \subset \mathbb{R}$ to $X$ such that $c(0)=x, c(l)=y, \quad$ and $d(c(t), c(t))=|t-\hat{t}|$ for all $t, \hat{t} \in[0, l]$. In particular, $c$ is an isometry and $d(x, y)=l$. The image $\alpha$ of $c$ is called geodesic (or metric) segment joining $x$ and $y$. When it is unique, this geodesic is denoted by $[x, y]$. The space $(X, d)$ is said to be geodesic space if every two points of $X$ are joined by a geodesic. The space $X$ is said to be uniquely geodesic if there is exactly one geodesic joining $x$ and $y$ for each $x, y \in X$. A subset $Y$ of $X$ is said to be convex if $Y$ includes every geodesic segment joining any two of its points.

A geodesic triangle $\Delta\left(x_{1}, x_{2}, x_{3}\right)$ in a geodesic space $(X, d)$ consists of three points $x_{1}, x_{2}, x_{3}$ in $X$ (the vertices of $\Delta$ ) and a geodesic segment between each pair of vertices (the edges of $\Delta$ ). A comparison triangle for geodesic triangle $\Delta\left(x_{1}, x_{2}, x_{3}\right)$ in $(X, d)$ is a triangle $\bar{\Delta}\left(x_{1}, x_{2}, x_{3}\right):=\Delta\left(x_{1}, x_{2}, x_{3}\right)$ in the Euclidean plane $E^{2}$ such that $d_{E^{2}}\left(\bar{x}_{i}, \bar{x}_{j}\right)=d\left(x_{i}, x_{j}\right)$ for $i, j \in\{1,2,3\}$.

A geodesic space is said to be a CAT (0) space if all geodesic triangles satisfy the following comparison axiom:

Let $\Delta$ be a geodesic triangle in $X$ and $\bar{\Delta}$ be a comparison triangle for $\Delta$, then $\Delta$ is said to satisfy $C A T(0)$ inequality if, for all $x, y \in \Delta$ and all comparison points $\bar{x}, \bar{y} \in$ $\Delta, d(x, y) \leq(\bar{x}, \bar{y})$.

If $x, y_{1}, y_{2}$ are points in a $C A T$ (0) space and if $y_{0}$ is the midpoint of the segment $\left[y_{1}, y_{2}\right]$, then the $C A T(0)$ inequality implies that

$$
d\left(x, y_{0}\right)^{2} \leq \frac{1}{2} d\left(x, y_{1}\right)^{2}+\frac{1}{2} d\left(x, y_{2}\right)^{2}-\frac{1}{4} d\left(y_{1}, y_{2}\right)^{2} .
$$

This is the $(C N)$ inequality of Bruhat and Tits [3]. By using the $(C N)$ inequality, it is easy to see that $C A T(0)$ spaces are uniformly convex. In fact (cf. [1], p. 163), a geodesic space is a CAT (0) space if and only if it satisfies the $(C N)$ inequality.

In 2008, Kirk and Panyanak [10] proposed the concept of $\Delta$-convergence which was originally introduced by Lim [16] to prove the CAT (0) space analogs of some Banach space results which involve weak convergence.

Let $\left\{x_{n}\right\}$ be a bounded sequence in a hyperbolic space $X$. For $x \in X$, define a continuous functional $r\left(.,\left\{x_{n}\right\}\right): X \rightarrow$
$[0, \infty)$ by:

$$
r\left(x,\left\{x_{n}\right\}\right)=\lim _{n \rightarrow \infty} \sup d\left(x, x_{n}\right) .
$$

The asymptotic radius $\rho=r\left(\left\{x_{n}\right\}\right)$ of $\left\{x_{n}\right\}$ is given by:

$$
\rho=\inf \left\{r\left(x,\left\{x_{n}\right\}\right): x \in X\right\}
$$

The asymptotic centre of a bounded sequence $\left\{x_{n}\right\}$ with respect to a subset $K$ of $X$ is defined as follows:

$$
A_{K}\left(\left\{x_{n}\right\}\right)=\left\{\begin{array}{c}
x \in X: r\left(x,\left\{x_{n}\right\}\right) \\
\leq r\left(y,\left\{x_{n}\right\}\right) \text { for any } y \in K
\end{array}\right\} .
$$

If the asymptotic centre is taken with respect to $X$, then it is simply denoted by $\left(A\left\{x_{n}\right\}\right)$. It is known that uniformly convex Banach spaces and even $C A T(0)$ spaces enjoy the property that "bounded sequences have unique asymptotic centers with respect to closed convex subsets".

A sequence $\left\{x_{n}\right\}$ in $X$ is said to $\Delta$-converge to $x \in X$ if $x$ is the unique asymptotic centre of $\left\{u_{n}\right\}$ for every subsequence $\left\{u_{n}\right\}$ of $\left\{x_{n}\right\}$. In this case, we write

$$
\Delta-\lim _{n} x_{n}=x \text { and call } x \text { as } \Delta-\lim \text { of }\left\{x_{n}\right\} .
$$

In the sequel, we shall need the following useful lemmas.

Lemma 2.1 ([7]). Let $(X, d)$ be a CAT (0) space.

(i) For $x, y \in X$ and $t \in[0,1]$, there exist a unique point $z \in[x, y]$ such that

$$
d(x, z)=t d(x, y) \text { and } d(y, z)=(1-t) d(x, y) .
$$

We use the notion $(1-t) x \oplus$ ty for the unique point $z$ satisfying (2.1).

(ii) For all $\mathrm{x}, \mathrm{y}, \mathrm{z} \in \mathrm{X}$ and $\mathrm{t} \in[0,1]$, we have

$$
d((1-t) x \oplus t y, z) \leq(1-t) d(x, z)+t d(y, z) .
$$

\section{Lemma 2.2}

(i) Every bounded sequence in a complete CAT (0) space always has a $\Delta$-convergent subsequence [7].

(ii) If $D$ is a closed convex subset of a CAT (0) space and if $\left\{x_{n}\right\}$ is a bounded sequence in $D$, then the asymptotic centre of $\left\{x_{n}\right\}$ is in D [5].

Lemma 2.3 ([15]). Let X be a complete CAT (0) space and let $\mathrm{x} \in \mathrm{X}$. Suppose that $\left\{t_{n}\right\}$ is a sequence in $[\mathrm{b}, \mathrm{c}]$ for some $\mathrm{b}, \mathrm{c} \in(0,1)$ and that $\left\{x_{n}\right\},\left\{y_{n}\right\}$ are sequence in $\mathrm{X}$ such that $\lim \sup _{n \rightarrow \infty} d\left(x_{n}, x\right) \leq r, \lim \sup _{n \rightarrow \infty} d\left(y_{n}, x\right) \leq$ $r$ and

$$
\lim _{n \rightarrow \infty} d\left(t_{n} x_{n} \oplus\left(1-t_{n}\right) y_{n}, x\right)=r,
$$

for some $r \geq 0$, then

$$
\lim _{n \rightarrow \infty} d\left(x_{n}, y_{n}\right)=0
$$

We now state few results to collect some basic properties regarding maps satisfying condition $(C)$ which states that:

"A map $T$ on a subset $K$ of a $C A T(0)$ space $X$ is said to satisfy condition (C), if

$\frac{1}{2} d(x, T x) \leq d(x, y) \Rightarrow d(T x, T y) \leq d(x, y)$, for all $\mathrm{x}, \mathrm{y} \in \mathrm{K}$. 


\section{Lemma 2.4}

(i) Every multi-valued non-expansive map satisfy condition (C).

(ii) If a multi-valued map T satisfies condition (C) and has a fixed point, Then $T$ is a quasi-non-expansive map.

Lemma 2.5 ([19]). Let $\mathrm{K}$ be a nonempty subset of a CAT (0) space $\mathrm{X}$ and let $T: K \rightarrow \mathrm{CB}(\mathrm{X})$ be a multi-valued map satisfying condition $(\mathrm{C})$, then for $\mathrm{x}, \mathrm{y} \in K$

either $\quad H(T x, T y) \leq d(x, y)$ or $H\left(T^{2} x, T y\right) \leq$ $d(T x, y)$ holds.

Lemma 2.6 ([9]). Let $\mathrm{K}$ be a nonempty closed convex subset of a uniformly convex hyperbolic space and $\left\{x_{n}\right\}$ a bounded sequence in $\mathrm{K}$ such that $A\left(\left\{x_{n}\right\}\right)=\{y\}$. If $\left\{y_{m}\right\}$ is another sequence in $\mathrm{K}$ such that $\lim _{m \rightarrow \infty} r\left(y_{m},\left\{x_{n}\right\}\right)=\rho$, then $\lim _{m \rightarrow \infty} y_{m}=y$.

\section{Main Results}

We start with proving a key lemma for later use.

Lemma 3.1. Let $K$ be a nonempty closed convex subset of a CAT (0) space $X$, let

$T, S: K \rightarrow C B(X)$ be two multi-valued maps satisfying condition (C). Let $\left\{x_{n}\right\}$ be a sequence defined by (1.1), such that $\alpha_{n} \in\left[\frac{1}{2}, b\right]$ and $\beta_{n} \in[a, b]$ or $\alpha_{n} \in[a, b]$ and $\beta_{n} \in[a, 1]$ for some $\mathrm{a}, \mathrm{b}$ with $0<a \leq b<1$. Then

(i) $\lim _{n \rightarrow \infty} d\left(x_{n}, z\right)$ exists for all $z \in F(T)$.

(ii) $\lim _{n \rightarrow \infty} d\left(x_{n}, T x_{n}\right)=0=\lim _{n \rightarrow \infty} d\left(x_{n}, S x_{n}\right)$.

Proof: Let $z \in F(T) \cap F(S)$, then it follows from (1.1) and Lemma 2.1(ii), Lemma 2.4(ii), that

$$
\begin{gathered}
d\left(x_{n+1}, z\right)=d\left(\beta_{n} z_{n} \oplus\left(1-\beta_{n}\right) T x_{n}, z\right) \\
\leq \beta_{n} d\left(z_{n}^{\prime}, z\right)+\left(1-\beta_{n}\right) d\left(T x_{n}, z\right), \\
=\beta_{n} d\left(z_{n}^{\prime}, S z\right)+\left(1-\beta_{n}\right) d\left(T x_{n}, z\right), \\
\leq \beta_{n} H\left(S y_{n}, S z\right)+\left(1-\beta_{n}\right) H\left(T x_{n}, T z\right), \\
\leq \beta_{n} d\left(y_{n}, z\right)+\left(1-\beta_{n}\right) d\left(x_{n}, z\right), \\
=\beta_{n} d\left(\alpha_{n} T x_{n} \oplus\left(1-\alpha_{n}\right) x_{n}, z\right)+\left(1-\beta_{n}\right) d\left(x_{n}, z\right), \\
\leq \alpha_{n} \beta_{n} d\left(T x_{n}, z\right)+\beta_{n}\left(1-\alpha_{n}\right) d\left(x_{n}, z\right) \\
+\left(1-\beta_{n}\right) d\left(x_{n}, z\right), \\
\leq \alpha_{n} \beta_{n} H\left(T x_{n}, T z\right)+\beta_{n}\left(1-\alpha_{n}\right) d\left(x_{n}, z\right) \\
+\left(1-\beta_{n}\right) d\left(x_{n}, z\right) \\
\leq \alpha_{n} \beta_{n} d\left(x_{n}, z\right)+\beta_{n}\left(1-\alpha_{n}\right) d\left(x_{n}, z\right) \\
+\left(1-\beta_{n}\right) d\left(x_{n}, z\right), \\
=d\left(x_{n}, z\right) .
\end{gathered}
$$

This implies that $\left\{d\left(x_{n}, z\right)\right\}$ is decreasing and bounded below for all $z \in F(T) \cap F(S)$ and this proves part (i). For further proceeding, we assume that $\lim _{n \rightarrow \infty} d\left(x_{n}, z\right)=c>$ 0 . Now, consider

$$
\begin{gathered}
d\left(y_{n}, z\right)=d\left(\alpha_{n} T x_{n} \oplus\left(1-\alpha_{n}\right) x_{n}, z\right) \\
\leq \alpha_{n} d\left(T x_{n}, z\right)+\left(1-\alpha_{n}\right) d\left(x_{n}, z\right), \\
\leq \alpha_{n} H\left(T x_{n}, T z\right)+\left(1-\alpha_{n}\right) d\left(x_{n}, z\right), \\
\quad \leq \alpha_{n} d\left(x_{n}, z\right)+\left(1-\alpha_{n}\right) d\left(x_{n}, z\right),
\end{gathered}
$$

$$
=d\left(x_{n}, z\right) \text {. }
$$

Applying $\lim \sup _{n \rightarrow \infty}$ on both sides of above inequality, we get

$$
\limsup _{n \rightarrow \infty} d\left(y_{n}, z\right) \leq \limsup _{n \rightarrow \infty} d\left(x_{n}, z\right)=c .
$$

Since $T$ satisfies condition $(C)$ and has a fixed point, therefore $T$ is quasi-non-expansive and hence

$$
\begin{gathered}
d\left(T x_{n}, z\right) \leq H\left(T x_{n}, T z\right), \\
\leq d\left(x_{n}, z\right),
\end{gathered}
$$

which implies

$$
\limsup _{n \rightarrow \infty} d\left(T x_{n}, z\right) \leq c .
$$

Also,

Implies

$$
\begin{aligned}
d\left(S y_{n}, z\right) & \leq H\left(S y_{n}, T z\right) \\
& \leq d\left(y_{n}, z\right) .
\end{aligned}
$$

$$
\limsup _{n \rightarrow \infty} d\left(S y_{n}, z\right) \leq \limsup _{n \rightarrow \infty} d\left(y_{n}, z\right) \leq c .
$$

Moreover,

$$
\lim _{n \rightarrow \infty} d\left(\beta_{n} z_{n}^{\prime} \oplus\left(1-\beta_{n}\right) T x, z\right)=\lim _{n \rightarrow \infty} d\left(x_{n+1}, z\right)=c .
$$

So, it follows from the Lemma (2.3), that

$$
\lim _{n \rightarrow \infty} d\left(z_{n}^{\prime}, T x_{n}\right)=0 .
$$

Now,

$$
\begin{gathered}
d\left(x_{n+1}, z\right)=d\left(\beta_{n} z_{n} \oplus\left(1-\beta_{n}\right) T x, z\right) \\
\leq\left(1-\beta_{n}\right) d\left(T x_{n}, z\right)+\beta_{n} d\left(z_{n}^{\prime}, z\right), \\
\leq\left(1-\beta_{n}\right) d\left(T x_{n}, z\right)+\beta_{n}\left[d\left(z_{n}^{\prime}, T x_{n}\right), d\left(T x_{n}, z\right)\right], \\
=d\left(T x_{n}, z\right)+\beta_{n} d\left(z_{n}^{\prime}, T x_{n}\right) .
\end{gathered}
$$

Implies

$$
c \leq \liminf _{n \rightarrow \infty} d\left(T x_{n}, z\right) .
$$

So that

$$
\limsup _{n \rightarrow \infty} d\left(T_{n}, z\right) \leq c .
$$

Conjunction of equation (3.4) and (3.5) gives

$$
\lim _{n \rightarrow \infty} d\left(z, T x_{n}\right)=c .
$$

On the other hand

$$
\begin{aligned}
d\left(z, T_{n}\right) & \leq d\left(z_{n}^{\prime}, T x_{n}\right)+d\left(z_{n}^{\prime}, z\right), \\
& =d\left(z_{n}^{\prime}, T x_{n}\right)+d\left(z_{n}^{\prime}, S z\right), \\
& \leq d\left(z_{n}^{\prime}, T x_{n}\right)+H\left(S y_{n}, S z\right), \\
& \leq d\left(z_{n}^{\prime}, T x_{n}\right)+d\left(y_{n}, z\right) .
\end{aligned}
$$

So, we have

$$
c \leq \liminf _{n \rightarrow \infty} d\left(y_{n}, z\right) .
$$

From equation (3.2) and equation (3.7), we get

$$
\lim _{n \rightarrow \infty} d\left(y_{n}, z\right)=c \text {. }
$$


Thus,

$$
c=\lim _{n \rightarrow \infty} d\left(y_{n}, z\right)=\lim _{n \rightarrow \infty} d\left(\alpha_{n} T x_{n} \oplus\left(1-\alpha_{n}\right) x_{n}, z\right) .
$$

Implies,

$$
\lim _{n \rightarrow \infty} d\left(T x_{n}, x_{n}\right)=0 .
$$

Note that the inequality $d\left(y_{n}, x_{n}\right) \leq \alpha_{n} d\left(T x_{n}, x_{n}\right)$ implies, on letting $n \rightarrow \infty$,

$$
\lim _{n \rightarrow \infty} d\left(x_{n}, y_{n}\right)=0 \text {. }
$$

Also, note that

$$
\begin{gathered}
d\left(x_{n+1}, x_{n}\right)=d\left(\beta_{n} z_{n} \oplus\left(1-\beta_{n}\right) T x_{n}, x_{n}\right), \\
\leq\left(1-\beta_{n}\right) d\left(T x_{n}, x_{n}\right)+\beta_{n} d\left(z_{n}^{\prime}, x_{n}\right), \\
\leq\left(1-\beta_{n}\right) d\left(T x_{n}, x_{n}\right)+\beta_{n}\left[d\left(T x_{n}, x_{n}\right)+d\left(T x_{n}, z_{n}^{\prime}\right)\right], \\
=d\left(T x_{n}, x_{n}\right)+\beta_{n} d\left(T x_{n}, z_{n}^{\prime}\right) \rightarrow 0 \text { as } n \rightarrow \infty .
\end{gathered}
$$

So that

$$
\begin{gathered}
d\left(x_{n+1}, y_{n}\right) \leq d\left(x_{n+1}, x_{n}\right)+d\left(x_{n}, y_{n}\right) \\
\rightarrow 0 \text { as } n \rightarrow \infty
\end{gathered}
$$

Furthermore,

$d\left(x_{n+1}, z_{n}^{\prime}\right) \leq d\left(x_{n+1}, x_{n}\right)+d\left(T x_{n}, x_{n}\right)+d\left(z_{n}^{\prime}, T x_{n}\right)$.

Hence, from equation (3.3), (3.9), (3.10), we have

$$
\lim _{n \rightarrow \infty} d\left(x_{n+1}, z_{n}^{\prime}\right)=0 \text {. }
$$

Assume $\frac{1}{2} \leq \alpha_{n} \leq b<1$ and $0<\alpha \leq \beta_{n} \leq b<1$.

Since,

$\frac{1}{2} \operatorname{dist}\left(x_{n}, T x_{n}\right) \leq \alpha_{n} d\left(x_{n}, T x_{n}\right)=d\left(x_{n}, y_{n}\right)$ for all $n \geq 0$.

By condition $(C)$, we have

$$
H\left(T x_{n}, T y_{n}\right) \leq d\left(x_{n}, y_{n}\right) \text { for all } n \geq 0 .
$$

Thus by using definition of non-expansive map and above condition $(\mathrm{C})$, we have

$$
\begin{gathered}
d\left(x_{n+1}, T x_{n+1}\right) \leq d\left(x_{n+1}, T^{2} x_{n+1}\right)+H\left(T^{2} x_{n+1}, T^{2} x_{n}\right) \\
+H\left(T^{2} x_{n}, T x_{n+1}\right), \\
\leq d\left(x_{n+1}, T^{2} x_{n+1}\right)+d\left(T x_{n+1}, T x_{n}\right)+d\left(T x_{n}, x_{n+1}\right), \\
\leq d\left(x_{n+1}, T^{2} x_{n+1}\right)+d\left(x_{n+1}, x_{n}\right)+d\left(T x_{n}, x_{n+1}\right), \\
=d\left(x_{n+1}, T^{2} x_{n+1}\right)+d\left(x_{n+1}, x_{n}\right)+\alpha_{n} d\left(x_{n}, z_{n}\right),
\end{gathered}
$$

which yields

$$
\lim _{n \rightarrow \infty} d\left(x_{n+1}, T x_{n+1}\right)=0
$$

Now,

$$
\begin{aligned}
& d\left(x_{n}, S x_{n}\right) \leq d\left(x_{n}, T x_{n}\right)+d\left(x_{n+1}, S y_{n}\right)+d\left(S x_{n}, S x_{n}\right) \\
& \quad \leq d\left(x_{n}, T x_{n}\right)+d\left(x_{n+1}, S y_{n}\right)+H\left(S x_{n}, S y_{n}\right) \\
& \leq d\left(x_{n}, T x_{n}\right)+d\left(x_{n+1}, S y_{n}\right)+d\left(x_{n}, y_{n}\right) \rightarrow 0 \text { as } n \rightarrow \infty \\
& \quad \text { Thus, }
\end{aligned}
$$

$$
\begin{gathered}
d\left(x_{n+1}, S x_{n+1}\right) \leq d\left(x_{n+1}, S^{2} x_{n+1}\right)+d\left(S^{2} x_{n+1}, S x_{n+1}\right) \\
\leq d\left(x_{n+1}, S^{2} x_{n+1}\right)+H\left(S^{2} x_{n+1}, S x_{n+1}\right) \\
\leq d\left(x_{n+1}, S^{2} x_{n+1}\right)+d\left(x_{n+1}, S x_{n+1}\right) \\
\leq d\left(x_{n+1}, S^{2} x_{n+1}\right)+\left[d\left(S x_{n+1}, z_{n}^{\prime}\right)+d\left(z_{n}^{\prime}, x_{n+1}\right)\right] \\
\leq d\left(x_{n+1}, S^{2} x_{n+1}\right)+H\left(S x_{n+1}, S y_{n}\right)+d\left(z_{n}^{\prime}, x_{n+1}\right) \\
\leq d\left(x_{n+1}, S^{2} x_{n+1}\right)+d\left(x_{n+1}, y_{n}\right)+d\left(z_{n}^{\prime}, x_{n+1}\right) .
\end{gathered}
$$

Letting $n \rightarrow \infty$ and utilizing (3.11) and (3.12), we have $\lim _{n \rightarrow \infty} d\left(S x_{n}, x_{n}\right)=0$. This completes the proof.

Regarding $\Delta$-convergence of the algorithm (1.1), we establish the following result.

Theorem 3.2. Assume that $\mathrm{K}, \mathrm{T}$ and $\left\{x_{n}\right\}$ be as in Lemma (3.1), then $\left\{x_{n}\right\} \Delta$-converges to a fixed point of $\mathrm{T}$.

Proof. It follows from Lemma (3.1) that $\left\{x_{n}\right\}$ is bounded and $\lim _{n \rightarrow \infty} d\left(S x_{n}, T x_{n}\right)=0$. We now let $w_{w}\left(x_{n}\right)=\cup A_{K}\left(\left\{u_{n}\right\}\right)$, where the union is taken over all subsequence $\left\{u_{n}\right\}$ of $\left\{x_{n}\right\}$. We claim that $w_{w}\left(x_{n}\right) \subset$ $F(T)$. Let $u \in w_{w}\left(x_{n}\right)$. Now, we show that $u \in T u$. For this we consider a sequence $z_{n k} \in T u$. Then it follows from Lemma (2.5) that either

$$
H(T x, T y) \leq d(x, y) \text { or } H\left(T^{2} x, T y\right) \leq d(T x, y) \text { holds. }
$$

If $H(T x, T y) \leq d(x, y)$ holds, then we have the following estimate:

$$
\begin{gathered}
d\left(z_{n_{k}}, u_{n}\right) \leq d\left(z_{n_{k}}, T u_{n}\right)+d\left(T u_{n}, u_{n}\right), \\
\leq H\left(T u, T u_{n}\right)+d\left(T u_{n}, u_{n}\right), \\
\quad \leq d\left(u, u_{n}\right)+d\left(T u_{n}, u_{n}\right) .
\end{gathered}
$$

In the second case, we have

$$
\begin{gathered}
d\left(z_{n k}, u_{n}\right) \leq d\left(z_{n k}, T u_{n}\right)+H\left(T u_{n}, T^{2} u_{n}\right)+H\left(T^{2} u_{n}, u_{n}\right) \\
\leq H\left(T u, T u_{n}\right)+d\left(u_{n}, T u_{n}\right)+H\left(T^{2} u_{n}, u_{n}\right) \\
\leq d\left(u, u_{n}\right)+d\left(T u_{n}, u_{n}\right)+H\left(T^{2} u_{n}, T u_{n}\right)+d\left(T u_{n}, u_{n}\right) \\
\leq d\left(u, u_{n}\right)+3 d\left(T u_{n}, u_{n}\right) .(3.14)
\end{gathered}
$$

Applying lim sup in (3.13) and (3.14), we have

$$
\begin{gathered}
r\left(z_{n k},\left\{u_{n}\right\}\right)=\lim _{n \rightarrow \infty} \sup d\left(z_{n k}, u_{n}\right) \leq \\
\leq \lim _{n \rightarrow \infty} \sup d\left(u, u_{n}\right)=r\left(u,\left\{u_{n}\right\}\right) .
\end{gathered}
$$

This implies that $\left|r\left(z_{n k},\left\{u_{n}\right\}\right)-r\left(u,\left\{u_{n}\right\}\right)\right| \rightarrow 0$ as $k \rightarrow$ $\infty$. It follows from Lemma (2.6) that $\lim _{k \rightarrow \infty} z_{n k}=u$. Since $T u$ is closed, therefore $u \in T u$; hence $u \in F(T)$. This shows that $w_{w}\left(x_{n}\right) \subset F(T)$.

To show that $\left\{x_{n}\right\} \Delta$ - converges to a fixed point of $T$, it is sufficient to show that $w_{w}\left(x_{n}\right)$ consist of exactly one point. Let $\left\{u_{n}\right\}$ be a subsequence of $\left\{x_{n}\right\}$. By Lemma 2.2(i)-(ii) that, there exists a subsequence $\left\{v_{n}\right\}$ of $\left\{u_{n}\right\}$ such that $\Delta-\lim _{n \rightarrow \infty} v_{n}=v \in K$. Let $A_{K}\left(\left\{u_{n}\right\}\right)=$ $\{u\}$ and $A_{K}\left(\left\{x_{n}\right\}\right)=x$. It is quiet easy to show that $u=v$ and $v \in F(T)$. We can complete the proof by proving that $x=v$. Assume contrary. Since $\left\{d\left(x_{n}, v\right)\right\}$ is convergent (Lemma 3.1(i)), then by the uniqueness of asymptotic centres

$$
\lim _{n \rightarrow \infty} \sup d\left(v_{n}, v\right)<\lim _{n \rightarrow \infty} \sup d\left(v_{n}, x\right)
$$




$$
\begin{aligned}
& \leq \lim _{n \rightarrow \infty} \sup d\left(x_{n}, x\right), \\
& <\lim _{n \rightarrow \infty} \sup d\left(x_{n}, v\right), \\
& =\lim _{n \rightarrow \infty} \sup d\left(v_{n}, v\right) .
\end{aligned}
$$

We have a contradiction. This completes the proof.

Remark 3.3. It is worth mentioning that theorem (3.2) (i) extends ([14], Theorem 4.6) for the class of generalized non-expansive maps in a $C A T$ (0) space (ii) gives multi-valued version of ([18], Theorem 5.3) in a $C A T(0)$ space (iii) gives $C A T(0)$ space analog of ([19], Theorem 3.8) and ([18], Theorem 3.3).

The following result gives a necessary and sufficient condition for strong convergence of the algorithm (1.1) in a complete $C A T(0)$ space.

Theorem 3.4. Assume that $\mathrm{K}, \mathrm{T}$ and $\left\{x_{n}\right\}$ be as in Lemma (3.1); in addition, if $\mathrm{X}$ is complete, then $\left\{x_{n}\right\}$ converges strongly to a fixed point of $\mathrm{T}$ if and only if $\liminf _{n \rightarrow \infty} d\left(x_{n}, F\right)=0$.

Proof. If $\left\{x_{n}\right\}$ converges to a point $p \in F(T)$, then $\lim _{n \rightarrow \infty} d\left(x_{n}, p\right)=0$. Since $0 \leq d\left(x_{n}, F\right) \leq d\left(x_{n}, p\right)$, we have $\liminf _{n \rightarrow \infty} d\left(x_{n}, F\right)=0$. Conversely, suppose that $\liminf _{n \rightarrow \infty} d\left(x_{n}, F\right)=0$. It follows from Lemma (3.1) (i) that $\lim _{n \rightarrow \infty} d\left(x_{n}, F\right)$ exists. Now, $\liminf _{n \rightarrow \infty} d\left(x_{n}, F\right)=$ 0 , reveals that $\lim _{n \rightarrow \infty} d\left(x_{n}, F\right)=0$. Next, we show that $\left\{x_{n}\right\}$ is a Cauchy sequence. Let $\epsilon>0$. Since $\lim _{n \rightarrow \infty} d\left(x_{n}, F\right)=0$, so for any given $\epsilon>0$, there exists a positive integer $\mathrm{n}_{1}$ such that $\mathrm{d}\left(\mathrm{x}_{\mathrm{n}}, \mathrm{F}\right)<\frac{\epsilon}{2}$. That is, there exists $\mathrm{p}_{0} \in \mathrm{F}$ such that $\mathrm{d}\left(\mathrm{x}_{\mathrm{n} 0}, \mathrm{p}_{0}\right)<\frac{\epsilon}{2}$. Hence, for any $\mathrm{n} \geq \mathrm{n}_{1}$ and $\mathrm{m} \geq 1$, we have

$$
\begin{gathered}
d\left(x_{n+m}, x_{n}\right) \leq d\left(x_{n+m}, p_{0}\right)+d\left(x_{n}, p_{0}\right) \\
\leq d\left(x_{n 0}, p_{0}\right)+d\left(x_{n}, p_{0}\right), \\
\leq 2 d\left(x_{n 0}, p_{0}\right)<2 \frac{\epsilon}{2}=\epsilon .
\end{gathered}
$$

This proves that $\left\{x_{n}\right\}$ is a Cauchy sequence in $X$ and so it must converge. Let $\lim _{n \rightarrow \infty} x_{n}=q$ (say). We claim that $q \in F$. Indeed, let $\epsilon_{0}>0$ then there exist an integer $\mathrm{n}_{1} \geq 1$ such that $\mathrm{d}\left(\mathrm{x}_{\mathrm{n}}, \mathrm{q}\right)<\frac{\epsilon_{0}}{4}$, for all $\mathrm{n} \geq \mathrm{n}_{1}$. Also $\lim _{n \rightarrow \infty} d\left(x_{n}, F\right)=0$ implies that there exist an integer $n_{2} \geq 1$ such that $d\left(x_{n}, F\right)<\frac{\epsilon_{0}}{4}$ for all $n \geq n_{2}$. Hence, there exists $\mathrm{p}_{0} \in \mathrm{F}$ such that

$$
d\left(x_{n j}, p_{0}\right)<\frac{\epsilon_{0}}{4}
$$

Then by the quasi-non-expansiveness of $\mathrm{T}$, we have

$$
\begin{gathered}
d(T q, q) \leq d\left(T q, p_{0}\right)+d\left(q, p_{0}\right) \\
\leq 2 d\left(q, p_{0}\right), \\
\leq 2\left(d\left(x_{n j}, q\right)+d\left(x_{n j}, p_{0}\right)\right) \\
\leq 2\left(\frac{\epsilon_{0}}{4}+\frac{\epsilon_{0}}{4}\right)=\epsilon_{0} .
\end{gathered}
$$

That is, $d(T q, q)<\epsilon_{0}$, for any arbitrary $\epsilon_{0}$. Therefore, we have $d(T q, q)=0$.

This completes the proof.
Remark 3.5. (i) Theorem (3.4) improves and extends [14, Theorem (5.2)] for the class of generalized non-expansive maps in CAT (0) space, (ii) Theorem (3.4) extends and improves [19, Theorem (3.7)] from Banach space setting to more general CAT (0) spaces.

Recall that a multi-valued map $T: D \rightarrow C B(D)$ is hemi-compact if any bounded sequence $\left\{x_{n}\right\}$ in $D$ satisfying $d\left(x_{n}, T x_{n}\right) \rightarrow 0$ as $n \rightarrow \infty$, has a convergent subsequence. A multi-valued map $T: D \rightarrow C B(D)$ is said to satisfy condition $(I)$ if there is a nondecreasing function $f:[0, \infty) \rightarrow[0, \infty)$ with $f(0)=0, f(t)>0$ for $t \in(0, \infty)$ s.t

$$
d(x, T x) \geq f(d(x, F)) \text { for all } x \in D .
$$

As an application of Lemma (3.1), we have the following strong convergence result.

Theorem 3.6. Assume that $\mathrm{K}, \mathrm{T}$ and $\left\{x_{n}\right\}$ be as in Lemma (3.1); in addition, if $\mathrm{T}$ is hemi-compact or satisfy Condition (I). Then $\left\{x_{n}\right\}$ converges strongly to a fixed point of $\mathrm{T}$.

\section{REFERENCES}

[1] M. Bridson, A. Haeiger, Metric spaces of Non-Positive Curvature, Springer-Verlag, Berlin, Heidelberg, 1999.

[2] K. S. Brown, Buildings, Springer-Verlag, New York, 1989.

[3] F.Bruhat, J. Tits, Groupes réductifs sur un corps local, Inst. Hautestudes Sci. Publ. Math., 41 (1972), 5251.

[4] S. Dhompongsa, A. Kaewkhao, B. Panyanak, Lims theorems for multi-valued maps in CAT (0) spaces, J. Math. Anal. Appl., 312 (2005), 478487.

[5] S. Dhompongsa, W. A. Kirk, B. Panyanak, Non-expansive set-valued mappings in metric and Banach spaces, J. Nonlinear Convex Anal., 8 (2007), 3545.10

[6] S. Dhompongsa, W. A. Kirk, B. Sims, Fixed points of uniformly lipschitzian mappings, Nonlinear Anal., TMA, 65 (2006), 762772.

[7] S. Dhompongsa, B. Panyanak. On convergence theorems in CAT (0) spaces, Com. Math. App., 56 (2008), 2572-2579.

[8] K. Goebel, S. Reich, Uniform Convexity, Hyperbolic Geometry and non-expansive Mappings, Marcel Dekker, Inc., New York, 1984.

[9] H. Fukhar-ud-din, A. R. Khan and M. A. A. Khan, An implicit algorithm for two nite families of non-expansive maps in hyperbolic spaces, fixed point theory and Applications 2012. 54

[10] W. A. Kirk, B. Panyanak, A concept of convergence in geodesic spaces, Nonlinear Anal., 68(2008) 3689-3696.

[11] W.A. Kirk, Geodesic geometry and Fixed point theory, in: Seminar of Mathematical Analysis (Malaga/Seville, 2002/2003), in: Colecc. Abierta, vol. 64, Univ. Sevilla Secr. Publ., Seville, 2003, pp. 195225.

[12] W. A. Kirk, Geodesic geometry and Fixed point theory II, in: 
International Conference on Fixed Point Theory and Applications, Yokohama Publ., Yokohama, 2004, pp. 113 142.

[13] U. Kohlenbach, L. Leustean, The approximate Fixed point property in product spaces, Nonlinear Anal., 66(4) (2007), 806-818.

[14] W. Laowang, B. Panyanak, Strong and $\Delta$-Convergence theorems for multi-valued mappings in CAT (0) spaces, J. Ineq. Appl., Vol. 2009, Article ID 730132, 16 pages.

[15] W. Laowang, B. Panyanak, Approximating Fixed point of non-expansive nonself mappings in CAT (0) spaces, fixed point theory and Applications 2009. 367274.
[16] T. C. Lim, Remarks on some fixed point theorems, Proc. Amer. Math. Soc., 60 (1976) 179-182.

[17] T. Suzuki Fixed point theorems and convergence theorems for some generalized non-expansive mappings, J. Math. Anal. Appl., 340(2008) 1088-1095.

[18] W. Phuengrattana, Approximating Fixed points of Suzuki-generalized non-expansive mappings, Nonlinear Anal. HS, 5(2011), 583-590.

[19] Z. Zuo, Y. Cui, Iterative approximations for generalized multi-valued mappings in Banach spaces, Thai J. Math., Vol. 9(2) (2011), 327336. 